\title{
Laparoscopic Ureterolithotomy: A Prospective Comparative Study
}

\author{
Naresh Kumar Giri, Narayan Thapa, Bikash Bikram Thapa, Bharat Bahadur Bhandari, \\ Bhairab Kumar Hamal
}

Department of Surgery, Nepalese Army Institute of Health Sciences, Shree Birendra Hospital, Kathmandu, Nepal.

ABSTRACT
Introduction: With the developments of non invasive and minimally invasive technology in the
management of urolithiasis, the choice of open surgery is rapidly decreasing. The optimal modality
of stone management is governed by multiple factors like stone parameters, patient character,
availability of technology and surgeon's skill. Open or laparoscopic ureterolithotomy can be used as
primary treatment option for large, impacted ureteral stones of more than $1.5 \mathrm{~cm}$ or as an adjunct
procedure in case of failed ESWL and attempted URS or PCNL.
Methods: This is a prospective comparative study to see the outcome of Trans-peritoneal
Laparoscopy Ureterolithotomy (TPLU) with Open Ureterolithotomy (OU). Out of 42 patients 21
had undergone laparoscopic ureterolithotomy and same number had undergone open surgery over
the period of two and half years. The variables evaluated were age, sex, stone character, operative
time, Visual Analogue Scale (VAS) for pain, complications and hospital stay.
Results: The patient and disease characteristics in both groups were comparable. Mean operative
time was $107.62 \pm 32.84$ mins in TPLU VS $65.48 \pm 15.72$ mins in OU group. Median hospital stay
was $2.19 \pm 1.78$ days in TPLU VS $4.62 \pm 1.53$ days in OU group. The pain score is significantly low
in TPLU than OU (p $<0.05$ ).
Conclusion: Laparoscopic ureterolithotomy is a safe and feasible treatment option for the selected
ureteric stone with comparable outcomes.
Key words: laparoscopy; stone; ureter

\section{INTRODUCTION}

Availability of Extracorporeal Shock Wave Lithotripsy (ESWL), Ureteroscopic Removal of Stone (URS), Retrograde Intrarenal Surgery (RIRS) and Percutaneous Nephrolithotomy (PCNL) have rapidly reduced the need of open surgery in urolithiasis management. Comparative series indicate that open ureterolithotomy can be replaced by laparoscopic ureterolithotomy in most situations. ${ }^{1}$

Patients with impacted ureteric stones have been treated successfully using laparoscopic ureterolithotomy, with less than $2 \%$ being converted to open surgery. ${ }^{2,3}$ Open or laparoscopy ureterolithotomy may be used as primary treatment option for large, impacted ureteral stones of more than $1.5 \mathrm{~cm}$ or as an adjunct procedure in case of failed ESWL and attempted URS or PCNL. ${ }^{4}$

We conducted a prospective comparative study between Open Ureterolithotomy (OU) versus Transperitoneal Laparoscopic Ureterolithotomy (TPUL) for the selected ureteric calculus.

\section{METHODS}

This is a prospective comparative study, conducted at Shree Birendra Hospital, Nepalese Army Institute of Health Sciences (NAIHS) from January
This work is licensed under: http:// creativecommons.org/licenses/by-nc-nd/4.0/
Correspondence: Narayan Thapa, Department of Surgery, Shree Birendra Hospital, Chhauni, Kathmandu.

Email: snthapa2061@gmail.com 


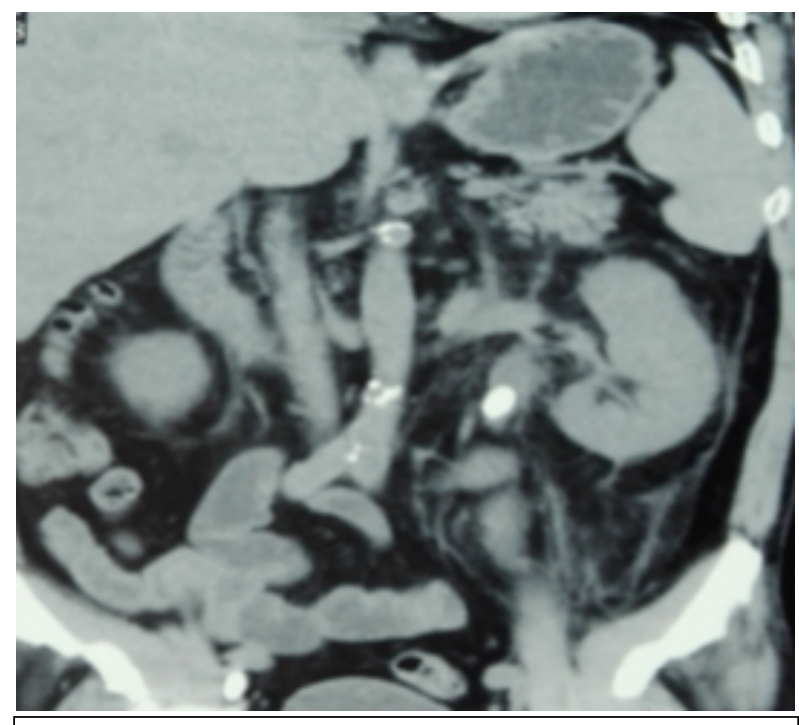

Figure 1: Preoperative NCCT KUB showing left proximal ureteric stone removed by laparoscopy

2014 to September 2016. A total of 48 patients were enrolled in the study and randomized in two groups; TPUL group and OU group by odd and even numbers selection respectively. However four patients refused randomization and opted for open surgical procedure and two patients in laparoscopic group were unfit for general anesthesia. Patient with stone size more than $1.5 \mathrm{~cm}$, failed ESWL, URS or PCNL were included in this study. Patients who refused randomization, having deranged coagulation profile, were unfit for general anesthesia were excluded from the study. The diagnosis was established with $\mathrm{X}$ - ray Kidney, Ureter and Bladder (KUB), Ultrasound KUB and either Intravenous Urogram (IVU) or Non-contrast Computed Tomography KUB (NCCT KUB) and stone size (longest diameter) was confirmed. Internal (double $\mathrm{J}$ stent) or external drainage (percutaneous nephrostomy) was performed in cases of obstructed nephropathy and or pyonephrosis. Urinary tract infection (UTI) was treated according to antibiotic sensitivity pattern. Informed written consent was obtained prior to surgical intervention.

All procedures were performed under general anesthesia by a team of surgeons. In cases of laparoscopic ureterolithotomy, cystoscopy and ureteric catheterization or DJ stenting was performed, which aided in intra-operative identification of ureter. All the patients were operated in lateral decubitus (kidney position) with or without bridge at the flank. In open ureterolithotomy standard subcostal/flank incision was given or incision was made depending upon the stone location. In Transperitoneal Laparoscopy Ureterolithotomy, pneumoperitoneum (12-15 mm $\mathrm{Hg}$ ) was created with infra-umbilical or lateral umbilical $10 \mathrm{~mm}$ port depending on patient built. Other two working ports were created at iliac fossa $(10 \mathrm{~mm})$ and subcostal $(5 \mathrm{~mm})$ in mid-clavicular line in cases of left side, whereas in cases of right side, $5 \mathrm{~mm}$ port was created at right iliac fossa and $10 \mathrm{~mm}$ in subcostal in midclavicular line. In some cases one additional port was created at flank for assistant.

Stones were identified by obvious bulge or pinching by Maryland forceps. Upward migration of the stone was prevented by applying a laparoscopic Babcock forceps on the ureter above the stone bulge. A longitudinal ureterotomy over the stone was given by electrocautery in all cases. The stone was disengaged and extracted using grasping forceps and retrieved through $10 \mathrm{~mm}$ port in collection bag. Ureterotomy was closed with intra-corporeal interrupted suture by 4-0 polygalactin. $16 \mathrm{~F}$ romovac drain was placed in paracolic gutter near to suture line in all cases.

Postoperative X-ray KUB was done to check the position of DJ stent and stone clearance on second postoperative day. Foleys catheter was removed on first postoperative day. The drain tube was removed on second post operative day and or when drain was less than $25 \mathrm{ml}$. The DJ stent was removed after 6 weeks of operation. Follow-up were done on 2 weeks and in 3 months and evaluated depending upon the presenting symptoms. The variables evaluated were age, sex, stone character, operative time, complications, Visual Analogue Scale (VAS) and hospital stay. The data were analyzed using SPSS 16.0 and expressed in mean \pm standard
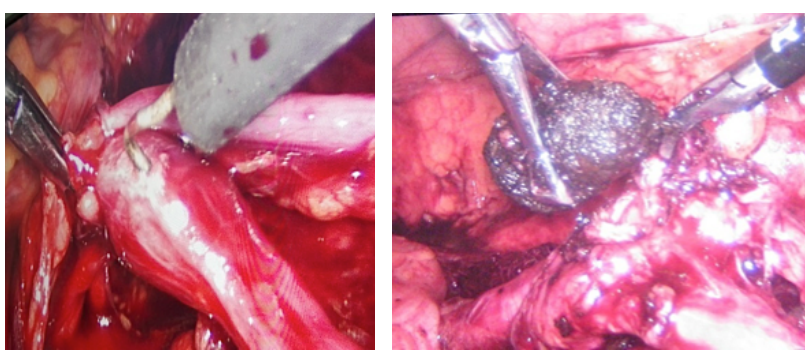

Figure 2a and 2b: location of stone with proximal control and stone removal 
Table 1: Comparison of disease characteristics between two groups

\begin{tabular}{|c|c|c|c|}
\hline Characteristics & $\begin{array}{c}\text { TPLU } \\
\text { group } \\
(\mathrm{n}=21)\end{array}$ & $\begin{array}{c}\text { OU group } \\
(\mathrm{n}=21)\end{array}$ & $\begin{array}{c}\text { P } \\
\text { value }\end{array}$ \\
\hline Mean age & $44.19 \pm 11.8$ & $40.05 \pm 12.2$ & 0.5 \\
\hline Male: female & $18: 3$ & $13: 8$ & \\
\hline $\begin{array}{c}\text { Stone site } \\
\text { (right: left) }\end{array}$ & $9: 12$ & $10: 11$ & 0.1 \\
\hline $\begin{array}{c}\text { Stone location } \\
\text { (proximal/ } \\
\text { Mid) }\end{array}$ & $16: 5$ & $13: 8$ & 0.7 \\
\hline $\begin{array}{c}\text { Stone size in } \\
\text { mm }\end{array}$ & $17 \pm 5$ & $15 \pm 5.2$ & 0.7 \\
\hline
\end{tabular}

deviation. The comparisons of diseases characteristics and outcome between two groups were done with Mann Whitney U test and Kruskalwallis test for independent variable and Wilcoxon test for dependent variables.

\section{RESULTS}

Statistically the two groups were comparable in terms of age, stone location and size of stone. (Table 1)

There was no statistically significant differences in two groups in terms of operative time, hospital stay and complications. However the pain score was significantly less in TPLU group. (Table 2)

\section{DISCUSSION}

With the development of non invasive and minimally invasive technology in the management of urolithiasis, the choice of open surgery is rapidly decreasing. ESWL, URS, RIRS and PCNL are the preferred modalities for treatment of ureteral stones and offer considerable advantages over open surgery. ${ }^{5}$ Still there is a role of open surgery in patients with complex calculus disease or in presence of anatomic and physiologic anomalies, as according to the Guidelines of the European Association of Urology. After the initial description of laparoscopic ureterolithotomy in 1979 by Wickham, now with the advancements in technique and experience, laparoscopy has become a highly effective modality in the treatment of complicated ureteral stones. ${ }^{6}$ The safety and feasibility of laparoscopic ureterolithotomy has already been demonstrated and it is a reasonable minimally invasive alternative to open surgery for ureteral stones not amenable to manage with other minimal invasive techniques. ${ }^{7,8}$

Laparoscopic ureterolithotomy can either be retroperitoneal or trans-peritoneal. The advantages of laparoscopic ureterolithotomy using transperitoneal route are large peritoneal space for instrument handling and intra-corporal suturing making procedure comparatively easy. ${ }^{9}$ Laparoscopic ureterolithotomy by trans-peritoneal approach has definite advantage over open ureterolithotomy. Traditionally, the open method requires large muscle cutting incision which is the main cause of pain and thus resulting in delayed recovery and long convalescence period with ugly looking scar. ${ }^{10}$

In open surgery there is often dilemma for exact site of skin incision and problem with stone migration along with complete clearance in case of multiple stones. The transperitoneal laparoscopic route has a definite advantage in avoiding such technical complications as calculus can be easily retrieved with further dissection of the ureter

\begin{tabular}{|c|c|c|c|}
\hline Parameters & TPLU group & OU group & P value \\
\hline Operative time (min) & $107.62 \pm 32.84$ & $65.48 \pm 15.72$ & 0.6 \\
\hline Total admission (days) & $2.19 \pm 1.786$ & $4.62 \pm 1.532$ & 0.08 \\
\hline \multirow[t]{2}{*}{ Complications (n) } & 3 & 2 & 0.9 \\
\hline & \multicolumn{3}{|c|}{ Visual Analogue pain score (VAS) } \\
\hline First POD & $4.1 \pm 1.0$ & $6.2 \pm 0.95$ & $<0.05$ \\
\hline Second POD & $2.0 \pm 0.5$ & $3.9 \pm 0.97$ & $<0.05$ \\
\hline
\end{tabular}




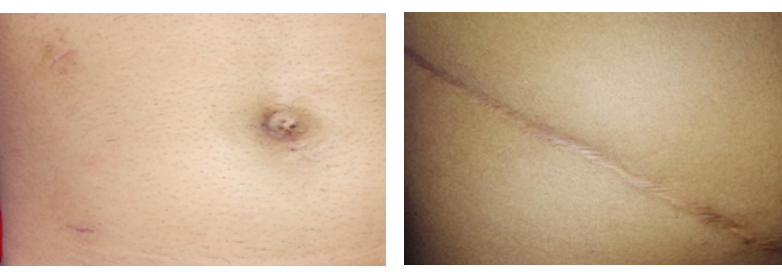

Figure 3a and 3b: Comparison of postoperative scar in laparoscopy and open surgery

without much increased morbidity. Keeley et al. reported the advantages of trans-peritoneal laparoscopic ureterolithotomy in which there is high probability of removing the entire stone burden in one procedure. ${ }^{11}$ In an evidence-based review by Skolarikos et al, the highest level of evidence was found for laparoscopic ureterolithotomy supporting the laparoscopic approach of stone extraction and mostly recommended for large impacted stones or when endoscopic techniques have failed. ${ }^{12}$

Success rate depends upon proper patient selection and surgical experience of laparoscopic technique. Historically success rates of transperitoneal ureterolithotomy range from 86 to $100 \%$. Basiri et al, who compared URS, PCNL and laparoscopy reported stone-free rates of $56 \%, 64 \%$, and $88 \%$ respectively. ${ }^{13}$ Better overall success rates in a single sitting is the advantage of open or laparoscopic ureterolithotomy over endoscopic techniques. ${ }^{14}$ In our laparoscopic series the stone clearance was $100 \%$ with conversion rate of $8.14 \%$ ( 2 out of 21) and re-operation in one patient due to persistent leak from ureter.

In the present study mean operative time was $107.62 \pm 32.84$ mins in case of TPLU group and $65.48 \pm 15.725$ mins in OU group. El-Feel et al. has reported the mean operative time of 145 minutes with range of $55-180$ minutes in laparoscopic ureterolithotomy. ${ }^{7}$ Skrepetis et al. compared open versus laparoscopic ureterolithotomy in 36 patients and concluded that the operation time was significantly longer in the laparoscopic group. ${ }^{15}$

In the present study, complications were recorded and graded according to Dindo-modified Clavien classification. One patient in the TPLU group developed leak and had to be managed by open surgery. The overall complication rate was $14.3 \%$ and $9.5 \%$ in TPLU and OU group respectively. The reported mean complications of laparoscopic transperitoneal urological surgeries ranged from 8.3 to
$19 \%{ }^{13,14,16,17}$ The mean hospital stay was $2.19 \pm$ 1.78 days and $4.62 \pm 1.53$ days in TPLU and OU respectively. The reported mean hospital stay in laparoscopic ureterolithotomy ranges from 3.8 to $5.8 \pm 2.3$ day. $^{7,} 16$ This allowed early ambulation and early resumption of oral intake in laparoscopic group.

Garg $\mathrm{M}$ et al, reported mean VAS on postoperative day 1 was $6.2 \pm 0.76$ in OU versus $3.1 \pm 0.38$ in TPLU and on the second postoperative day mean VAS was $4.8 \pm 0.72$ in OU versus $2.4 \pm 0.49$ for TPLU respectively. ${ }^{18}$ The pain score was significantly lower in TPLU group than OU group in our study with $\mathrm{p}$ value less than 0.05 .

\section{CONCLUSIONS}

Laparoscopic ureterolithotomy can be considered as a safe and effective procedure with minimal morbidity. It is associated with less postoperative pain, less analgesic requirement, shorter hospital stay and early convalescence in comparison to open ureterolithotomy.

\section{REFERENCES}

1. Paik ML, Resnick MI. Is there a role for open stone surgery? Urol Clin North Am. 2000 May;27(2):323-31. https://doi.org/10.1016/S0094-0143(05)70261-5

2. Honeck P, Wendt-Nordahl G, Krombach P, Bach T, Hacker A, Alken P, et al. Does open stone surgery still play a role in the treatment of urolithiasis? Data of a primary urolithiasis center. J Endourol. 2009 Jul;23(7): 1209-12.

https://doi.org/10.1089/end.2009.0027

3. Almeida GL, Heldwein FL, Graziotin TM, Schmitt CS, Teloken C. Prospective trial comparing laparoscopy and open surgery for management of impacted ureteral stones. Actas Urol Esp. 2009 Nov;33(10):1108-14. https://doi.org/10.1016/S0210-4806(09)73189-4

4. Singh V, Sinha RJ, Gupta DK, Kumar M, Akhtar A. Transperitoneal versus retroperitoneal laparoscopic ureterolithotomy: a prospective randomized comparison study. J Urol. 2013 Mar;189(3):940-5.

https://doi.org/10.1016/j.juro.2012.09.114

5. Preminger GM, Tiselius HG, Assimos DG, Alken P, Buck AC, Gallucci M, et al. 2007 Guideline for the management of ureteral calculi. Eur Urol. 2007 Dec; 52(6):1610-31.

https://doi.org/10.1016/j.eururo.2007.09.039

6. JE. W, editor. The surgical treatment of renal lithiasis. New York: Churchill Livingstone; 1979.

7. El-Feel A, Abouel-Fettouh H, Abdel-Hakim AM. Laparoscopic transperitoneal ureterolithotomy. J Endourol. 2007 Jan;21(1):50-4

https://doi.org/10.1089/end.2006.0141

8. Mandhani A, Kapoor R. Laparoscopic ureterolithotomy for lower ureteric stones: Steps to make 
it a simple procedure. Indian J Urol. 2009 Jan;25(1):

140-2.

https://doi.org/10.4103/0970-1591.45556

9. Henkel TO, Rassweiler J, Alken P. Ureteral laparoscopic surgery. Ann Urol (Paris). 1995;29(2): 61-72.

10. Harewood LM, Webb DR, Pope AJ. Laparoscopic ureterolithotomy: the results of an initial series, and an evaluation of its role in the management of ureteric calculi. Br J Urol. 1994 Aug;74(2):170-6.

https://doi.org/10.1111/j.1464-410X.1994.tb16581.X

11. Keeley FX, Gialas I, Pillai M, Chrisofos M, Tolley DA. Laparoscopic ureterolithotomy: the Edinburgh experience. BJU Int. 1999 Nov;84(7):765-9. https://doi.org/10.1046/j.1464-410x.1999.00287.x

12. Skolarikos A, Papatsoris AG, Albanis S, Assimos D. Laparoscopic urinary stone surgery: an updated evidence-based review. Urol Res. 2010 Oct;38(5): 337-44.

https://doi.org/10.1007/s00240-010-0275-4

13. Simforoosh N, Basiri A, Danesh AK, Ziaee SA, Sharifiaghdas F, Tabibi A, et al. Laparoscopic management of ureteral calculi: a report of 123 cases. Urol J. 2007 Summer;4(3):138-41.

14. Ko YH, Kang SG, Park JY, Bae JH, Kang SH, Cho DY, et al. Laparoscopic ureterolithotomy as a primary modality for large proximal ureteral calculi: comparison to rigid ureteroscopic pneumatic lithotripsy. J Laparoendosc Adv Surg Tech A. 2011 Jan-Feb;21(1): 7-13.

https://doi.org/10.1089/lap.2010.0340

15. Skrepetis K, Doumas K, Siafakas I, Lykourinas M. Laparoscopic versus open ureterolithotomy. A comparative study. Eur Urol. 2001 Jul;40(1):32-6; discussion 7.

https://doi.org/10.1159/000049746

16. Feyaerts A, Rietbergen J, Navarra S, Vallancien G, Guillonneau B. Laparoscopic ureterolithotomy for ureteral calculi. Eur Urol. 2001 Dec;40(6):609-13. https://doi.org/10.1159/000049845

17. Vallancien G, Cathelineau X, Baumert H, Doublet JD, Guillonneau B. Complications of transperitoneal laparoscopic surgery in urology: review of 1,311 procedures at a single center. J Urol. 2002 Jul;168(1): 23-6.

https://doi.org/10.1016/S0022-5347(05)64823-9

18. Garg M, Singh V, Sinha RJ, Sankhwar SN, Kumar M, Kumar A, et al. Prospective Randomized Comparison of Open versus Transperitoneal Laparoscopic Ureterolithotomy: Experience of a Single Center from Northern India. Curr Urol. 2013 Nov;7(2):83-9.

https://doi.org/10.1159/000356254 